\title{
Vascular Hyperpermeability, Angiogenesis, and Stroma Generation
}

\author{
Janice A. Nagy, Ann M. Dvorak, and Harold F. Dvorak \\ Center for Vascular Biology Research and the Department of Pathology, Beth Israel Deaconess \\ Medical Center and Harvard Medical School, Boston, Massachusetts 02115 \\ Correspondence: hdvorak@bidmc.harvard.edu
}

It has been known for more than half a century that the tumor microvasculature is hyperpermeable to plasma proteins. However, the identity of the leaky vessels and the consequences of vascular hyperpermeability have received little attention. This article places tumor vascular hyperpermeability in a broader context, relating it to (1) the low-level "basal" permeability of the normal vasculature; (2) the "acute," short-term hyperpermeability induced by vascular permeability factor/vascular endothelial growth factor (VPF/VEGF-A) and other vascular permeabilizing agents; and (3) the "chronic" hyperpermeability associated with longer-term exposure to agents such as VPF/VEGF-A that accompanies many types of pathological angiogenesis. Leakage of plasma protein-rich fluids is important because it activates the clotting system, depositing an extravascular fibrin gel provisional matrix that serves as the first step in stroma generation.

\begin{abstract}
$A^{11}$ cells require a continuing supply of Anutrients and a means of clearing waste products. Vertebrates have solved this problem by developing a vascular system that projects into all organs and most tissues. The vertebrate vasculature is often described as "closed," but it is sufficiently "open" (i.e., "permeable") to allow the ready exchange of small molecule nutrients and waste products between the blood and tissues. Plasma proteins also need to cross the vascular barrier, at least in small amounts. Albumin, for example, transports fatty acids and some vitamins and immunoglobulins that are required for host defense. Vascular permeability, then, is essential for the health of normal tissues and is also an important feature of many
\end{abstract}

disease states (e.g., cancer, in which it is greatly increased).

\section{WHAT IS VASCULAR PERMEABILITY AND HOW SHOULD IT BE MEASURED?}

Surprisingly, there is considerable disagreement as to the meaning of the term vascular permeability and the methods by which it should be measured (Bates and Harper 2003). Permeability is a complicated process that, however defined, is affected by many different variables. These include the intrinsic properties of the different types of microvessels involved (i.e., capillaries, venules, "mother" vessels); the size, shape, and charge of extravasating molecules

Editors: Michael Klagsbrun and Patricia D'Amore

Additional Perspectives on Angiogenesis available at www.perspectivesinmedicine.org

Copyright (C) 2012 Cold Spring Harbor Laboratory Press; all rights reserved; doi: 10.1101/cshperspect.a006544

Cite this article as Cold Spring Harb Perspect Med 2012;4:a006544 
J.A. Nagy et al.

(water and solutes); the anatomic pathways (trans- vs. intercellular [paracellular]) through which molecules cross the endothelial cell barrier; the time course over which permeability is measured; and the vascular beds that are being investigated. A related issue, that of the passage of inflammatory cells across the microvasculature, is reviewed elsewhere (Feng et al. 1998; Kamei and Carman 2010).

\section{The Physiologists' View of Vascular Permeability}

Over the last half century, eminent physiologists have investigated the mechanisms by which plasma components cross the vascular barrier (Pappenheimer 1953; Rippe and Haraldsson 1994; Michel and Curry 1999; Guyton and Hall 2000; Bates and Harper 2003; Curry 2005). They recognized that capillaries were the vascular segment involved in molecular exchange in normal tissues and that water, gases, and other small molecules crossed capillary endothelial cells freely, whereas the passage of larger molecules such as plasma proteins was tightly restricted. Physiologists have often regarded capillary endothelium as a passive barrier, likening it to a thin, cellophane-like membrane that is punctuated by large numbers of small pores and smaller numbers of large pores. They postulated that the numerous small pores allowed the ready passage of small molecules and that the smaller number of large pores allowed limited extravasation of plasma proteins. With these assumptions in mind they developed elegant methods for investigating the flux of water and of plasma solutes across individual cannulated microvessels and for calculating the important parameters that govern permeability: (1) vascular surface area available for molecular exchange; (2) thickness of the vessel wall; (3) hydraulic conductivity, a measure of capillary permeability to water; (4) reflection coefficient, a measure of solvent drag in relation to that of water; (5) diffusion; and (6) transvascular pressure gradients. For a given capillary, diffusion is the most important of these for the exchange of small molecules and depends on differences in solute concentration across vascular endothelium. Diffusion is importantly affected by the molecular properties of solute; for example, despite a substantial concentration gradient, diffusion of a large molecule such as albumin is $\sim 1000$-fold less than that of water (Pappenheimer 1953; Guyton and Hall 2000). Therefore, for large molecules such as plasma proteins, flux is largely determined by transvascular hydrostatic and osmotic pressure differences, by hydraulic conductivity, and by the reflection coefficient characteristic of a given solute.

\section{Permeability as Understood by Vascular Biologists}

Vascular biologists have used the term vascular permeability in a different sense. Rather than being concerned with the filtration rate across a single cannulated microvessel, they have sought to measure the net amount of a solute, often a macromolecule such as plasma albumin, that has crossed a vascular bed and accumulated in the interstitium in response to a vascular permeabilizing agent or at a site of pathological angiogenesis. Generally, the vessels present are a mixture of several different types, and the measurements made combine together all of the factors that regulate extravasation, including both intrinsic properties of the blood vessels as well as extrinsic properties such as blood flow and the molecular properties of the solute.

To obtain this type of information, we introduced the Miles assay (Miles and Miles 1952) into tumor biology many years ago (Dvorak et al. 1979b). Typically, a dye such as Evans blue that binds noncovalently to albumin is injected intravenously and its accumulation is measured in a skin test site, a tumor, etc. Permeability is then defined as the amount of albumin-dye complex that is present at some time, for example, $30 \mathrm{~min}$, after Evans blue injection. The intensity of local bluing observed visually provides sufficient information for some purposes. For example, we originally identified VPF/VEGF-A as a vascular permeabilizing agent using this assay in guinea pig skin (Dvorak et al. 1979b) and used local bluing 
Permeability, Angiogenesis, and Stroma Generation

to evaluate column fractions in the original purification of VPF/VEGF-A (Senger et al. 1983). Quantitative measurements can also be made by extracting the dye from tissues and measuring it spectrophotometrically (Nagy et al. 2008b). A limitation of the Miles assay is that it does not distinguish between dye that has extravasated from that which is present within the vasculature. However, serious error does not result if (1) comparisons of permeability are made at similar test sites in the same animal and (2) intravascular volumes are small relative to the amounts of dye that have leaked. Another limitation is that the Miles assay measures net accumulation of dye-albumin complex over a period of time, and return of extravasated molecules to the circulation, either by way of capillaries or lymphatics, is not considered. Despite these limitations the Miles assay is widely used and has provided much useful information.

However, in tumors and in other examples of pathological angiogenesis, the vasculature undergoes dramatic structural and functional changes and is not comparable to that of adjacent normal control tissues. In such instances it is desirable to measure both the content of macromolecular tracer within the vasculature and the dye that has extravasated. Flushing the vasculature to remove intravascular dye has been used but can result in error as perfusion may be incomplete and/or may extract extravasated dye. A better approach is to use a double tracer method (e.g., combining ${ }^{131} \mathrm{I}$ - and ${ }^{125} \mathrm{I}$-albumin or Evans blue dye and ${ }^{125}$ I-albumin [Nagy et al. 2008b]). The first tracer is used to measure total albumin accumulation in a tumor over $30 \mathrm{~min}$ (i.e., albumin both leaked and intravascular). The second tracer, injected $5 \mathrm{~min}$ before tumor harvest, measures only albumin that is present within the blood vasculature, because extravascular leakage is negligible over that short time period. By subtracting values of the second tracer from that of the first, one obtains quantitative measures of (1) intravascular plasma volume, an excellent, unbiased measure of the extent of new blood vessel formation and (2) the volume of leaked plasma.

\section{IN VITRO PERMEABILITY ASSAYS}

The assays described above measure permeability in living animals. However, many investigators have used in vitro assays to measure molecular flux across lawns of confluent endothelial cells cultured on membrane filters in transwell chambers. These assays are appealing in that they are easy to perform and avoid the complexities of experiments in living animals. However, they suffer from some important limitations. Confluent cultured endothelial cell monolayers, whether isolated from large or small vessels, are generally leakier than normal blood vessels in vivo for several reasons: (1) absence of normal basement membrane; (2) lack of pericytes or smooth muscle cells; and (3) relative loss of cytoplasmic vesicles and vacuoles, structures that are numerous in endothelial cells in vivo and that provide an important pathway for macromolecular extravasation (Palade 1988; Feng et al. 1996, 1999b). Cultured endothelial cell monolayers, therefore, most closely resemble "mother" vessels, the first new type of blood vessel to develop in tumors, wounds, etc.; therefore, they perhaps best model the vascular hyperpermeability associated with pathological angiogenesis. Finally, the kinetics of leakage in response to agents such as VEGF-A often differs markedly from that in vivo. In vivo, leakage in response to a single exposure to VEGF-A begins within a minute and is largely complete by $\sim 20-30 \mathrm{~min}$. In contrast, increased permeability often develops more slowly in cultured endothelium and may continue over a period of hours, suggesting that the permeability observed results from a longerterm loosening of intercellular connections.

\section{VASCULAR PERMEABILITY OCCURS IN THREE DIFFERENT SETTINGS}

Low levels of vascular permeability to plasma proteins are essential for the health of normal tissues and these levels may vary considerably in different organs and tissues and in response to different physiological stimuli (e.g., local temperature, exercise). However, it is important to distinguish between the basal permeability 
J.A. Nagy et al.

levels of normal tissues and the greatly increased levels of plasma protein extravasation that occur in pathology. These hyperpermeable states may be acute or chronic and differ from each other and from basal levels of permeability with respect to the vessels that leak, the composition of the extravasate, and the anatomic pathways that solutes follow in crossing vascular endothelium. Each of the three types of permeability is now discussed in turn.

\section{Basal Vascular Permeability}

Molecular exchange in normal tissues takes place primarily in capillaries. The molecules exchanged consist largely of water, gases, and small solutes such as salts and sugars. Exchange is driven largely by diffusion and only small amounts of plasma proteins extravasate. Basal vascular permeability (BVP) varies considerably in different normal tissues and is modulated by changes in blood flow, opening of previously closed vessels, etc.

How do plasma and solutes of different size traverse capillaries? No "pores" of the type that had been postulated by physiologists have been found in normal capillary endothelium. Nonetheless, it was not difficult to explain the transport pathways followed by small molecules. Water, lipophilic solutes (e.g., gases such as $\mathrm{O}_{2}$ and $\mathrm{CO}_{2}$ ), and other small solutes are able to pass between endothelial cells or through them by receptor-mediated transcytosis, and also cross through the endothelial fenestrae found in some capillaries. Small proteins such as horseradish peroxidase (MW $44 \mathrm{kDa}$ ) can pass through interendothelial cell junctions, but do so at rates that are much slower than their overall entry into tissues (Karnovsky 1967; Dvorak 2007a).

Plasma proteins such as albumin (MW 69 $\mathrm{kDa}$ ) are too large to pass between intact endothelial cells. A solution to their extravasation was offered by George Palade who observed that capillary endothelium contained large numbers of small $(50-100 \mathrm{~nm}$ diameter $)$, uncoated vesicles, now commonly referred to as caveolae (Palade 1988). The majority of caveolae are found connected to the luminal and abluminal plasma membranes by stomata that are generally closed by thin diaphragms (Fig. 1). Little is known about the composition of these diaphragms other than that they contain a unique protein, PV-1, and likely sulfated proteoglycans (Stan 2007). Palade postulated that caveolae shuttled across capillary endothelium carrying cargoes of plasma fluid and proteins and this was subsequently demonstrated experimentally with tracers (reviewed in Dvorak 2007a). Thus, it seemed that the large pores postulated by physiologists were not pores at all but shuttling caveolae, and that transport of large molecules across capillaries was anything but passive. This concept has recently been challenged by the finding that caveolin-1 ${ }^{-/-}$ mice, which lack caveolae, actually clear plasma albumin more rapidly than their wild-type counterparts (Schubert et al. 2002; Rosengren et al. 2006). Further work will be required to explain

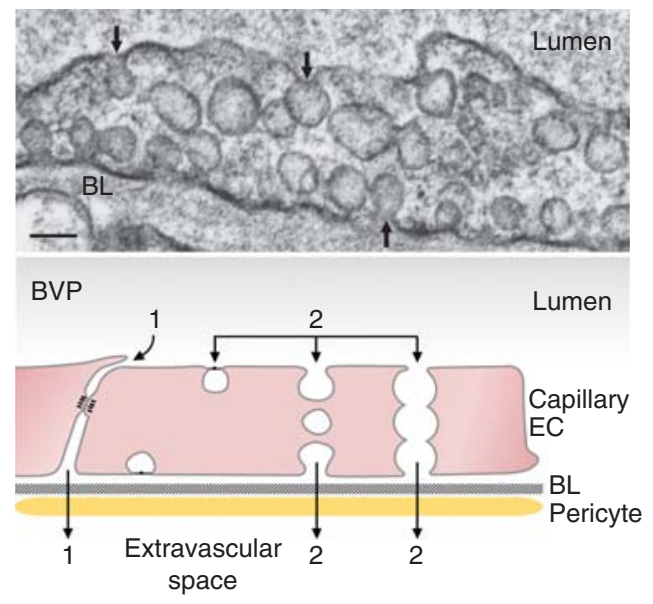

Figure 1. Basal vascular permeability (BVP). (Upper) Electron micrograph illustrating a typical capillary endothelial cell with numerous caveolae. Many of these are connected to the luminal or abluminal plasma membranes (arrows). Scale bar, $100 \mathrm{~nm}$. (Lower) Schematic diagram illustrating pathways by which molecules can cross the capillary barrier. (1) Interendothelial cell cleft, (2) caveolae that shuttle across the capillary endothelium or form a chain of vesicles connecting the lumen and albumen. (BL) Basal lamina, (EC) endothelial cell, (BVP) basal vascular permeability. (Figure adapted from Nagy et al. 2008a; reproduced, with permission, from Springer (C) 2008.) 
this conundrum, but it should be noted that capillary endothelium in caveolin-1 $1^{-/}$mice retain $10 \%-20 \%$ of the uncoated caveolae-sized vesicles present in wild-type mice, though these vesicles do not stain for caveolin-1 (Chang et al. 2009a).

\section{Acute Vascular Hyperpermeability}

A rapid increase in vascular permeability occurs when the microvasculature is exposed acutely to vascular permeabilizing factors such as VPF/VEGF-A, histamine, serotonin, PAF (platelet activating factor), etc. Some of these (e.g., histamine, serotonin, VPF/VEGF-A) are stored in tissue mast cells (Boesiger et al. 1998; Galli 2000) and so may be released by agents that cause mast cell degranulation (e.g., exposure to allergens, insect bites). Single exposure to any of these permeability factors results in a rapid but self-limited (complete by $20-$ $30 \mathrm{~min}$ ) influx of plasma into the tissues. Both the quantity of extravasated fluid and its composition differ strikingly from that in BVP. The fluid passing from the circulation into normal tissues under basal conditions is a plasma filtrate (i.e., a fluid consisting largely of water and small solutes but containing only small amounts of plasma proteins). However, the fluid that extravasates in acute vascular hyperpermeability $(\mathrm{AVH})$ is rich in plasma proteins approaching the levels found in plasma (i.e., an exudate). The consequences of plasma fibrinogen leakage and resulting extravascular clotting are discussed below under chronic vascular hyperpermeability $(\mathrm{CVH})$.

AVH also differs from BVP in that vascular leakage takes place not from capillaries but from postcapillary venules (Majno et al. 1961, 1969). Whereas capillaries have a flattened endothelium, venules are lined by taller, cuboidal endothelium. Majno proposed that histamine and other vascular permeabilizing agents induced endothelial cells to contract and pull apart to form intercellular (paracellular) gaps of sufficient size to permit plasma protein extravasation.

More recently, a structure was discovered in venular endothelium, the vesiculo-vacuolar organelle (VVO), which offers an alternative, transendothelial cell route for plasma extravasation (Kohn et al. 1992; Dvorak et al. 1996; Feng et al. 1996, 1997, 2000). VVOs are grape-like clusters comprised of hundreds of uncoated, cytoplasmic vesicles and vacuoles that together form an organelle that traverses venular endothelial cytoplasm from lumen to ablumen (Figs. 2A,B and 3A). VVOs also open to the interendothelial cell cleft, either below or above sites of specific junctional (adherens or tight junctions) attachment (Fig. 3A). The vesicles and vacuoles comprising VVOs vary in size from caveolae-sized vesicles to vacuoles with volumes as much as 10-fold larger (Feng et al. 1999a). These vesicles and vacuoles are linked to each other and to the plasma membrane by stomata that are normally closed by thin diaphragms that appear similar to those found in caveolae. We conjectured some years ago that VVOs formed from the linking together of individual caveolae, and that larger vesicles and vacuoles resulted from the fusion of two or more caveolae-sized vesicles (Feng et al. 1999a). Evidence for this was that the smallest VVO vesicles were indistinguishable structurally from caveolae; further, larger VVO vesicles and vacuoles have volumes that do not fall on a continuum but have a modal distribution (i.e., occur as multiples of the volume of caveolae, the unit vesicle, up to 10 mers). However, more recent data render this conclusion less likely. As in capillary endothelium, caveolin-1 staining, $50-100 \mathrm{~nm}$ diameter, uncoated vesicles were greatly reduced in the venular endothelium of caveolin-1 $1^{-/}$mice, but VVOs were not diminished in either number or composition (Chang et al. 2009a). It would seem, therefore, that VVOs are comprised of a population of uncoated vesicles and vacuoles that is distinct from caveolae, though in wild-type mice many stain with anti-caveolin-1 antibodies. Whether VVOs somehow take the place of caveolae in caveolin-1 ${ }^{-/-}$mice and thereby contribute to the increased permeability observed in these animals needs to be investigated. A further conundrum is that although VVOs appear structurally normal in caveolin- $1^{-/-}$mice, AVH is greatly reduced 
J.A. Nagy et al.
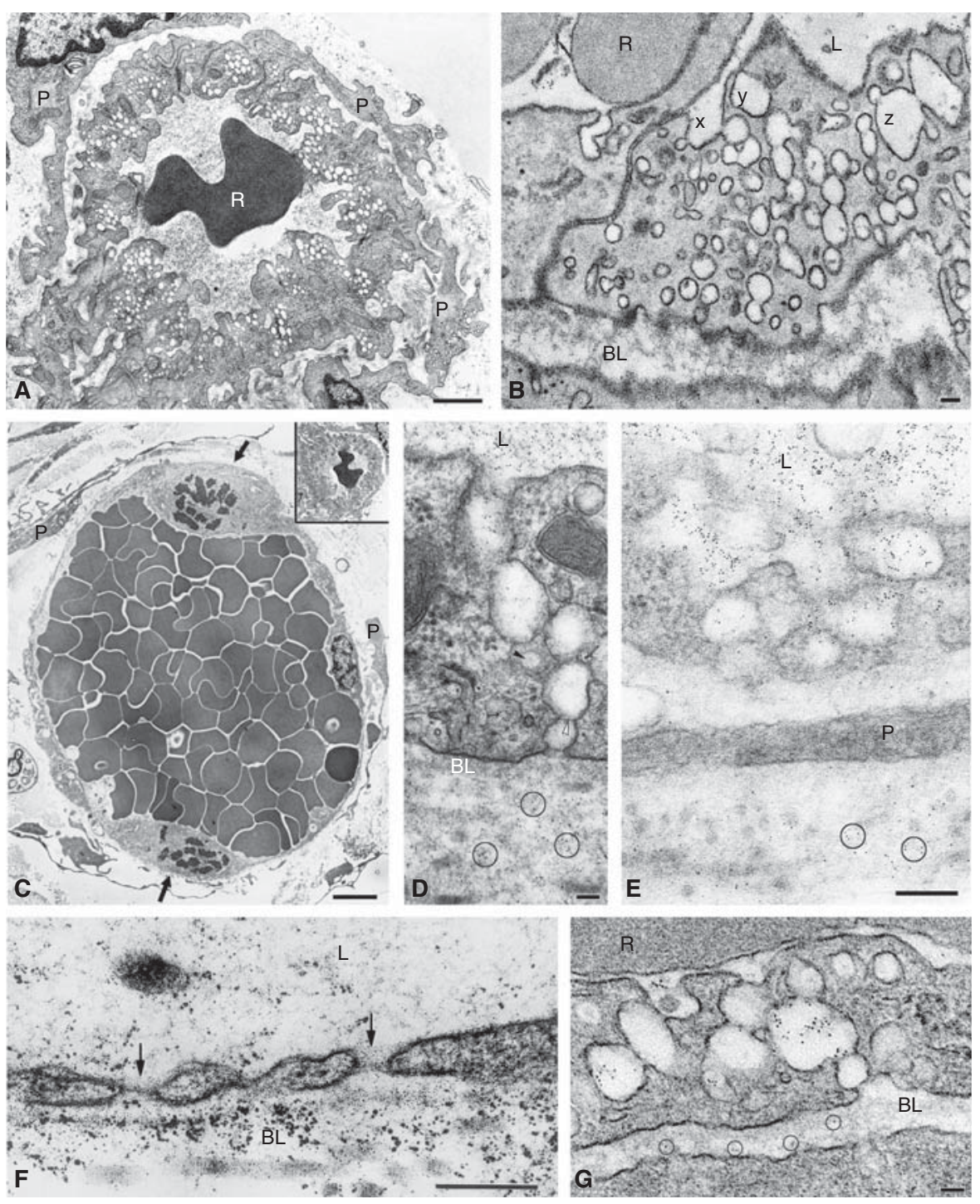

Figure 2. Transmission electron micrographs of normal venules $(A, B)$ and hyperpermeable microvessels $(C-G)$. (A) Typical normal venules lined by cuboidal endothelium. The cytoplasm contains prominent VVOs and is enveloped by a complete coating of pericytes $(\mathrm{P})$. (R) Red blood cell. (B) Ultrathin section from a set of 36 consecutive serial sections demonstrates three sets of VVO vesicles $(\mathrm{x}, \mathrm{y}, \mathrm{z})$ that could be traced from the vascular lumen to albumen. $(C)$ Mother vessels (MVs) are characterized by greatly enlarged size, extensive endothelial cell thinning, striking reduction in VVOs and other cytoplasmic vesicles, prominent nuclei that project into the vascular lumen, mitotic figures (arrows), and pericyte (P) detachment. MV lumens are packed with red blood cells, indicating extensive plasma extravasation. (Inset) The normal venule depicted in $A$ is reproduced in $C$ at the same magnification as the MVs to illustrate relative size differences. $(D-G)$ Leakage of ferritin tracer (black dots, some encircled) through MV VVOs $(D, E)$ and fenestrae ( $F$, arrows), and through VVOs of a normal venule in response to VPF/VEGF-A $(G)$. Scale bars, $1 \mu \mathrm{m}(A) ; 50 \mathrm{~nm}(B, D, G) ; 5 \mu \mathrm{m}(C) ; 200 \mathrm{~nm}(E, F)$. $(A, C$, and $E$ adapted from Nagy et al. 2006; reproduced, with permission, from Nature Publishing (C) 2006. $D$ adapted from Kohn et al. 1992; reproduced, with permission, from Nature Publishing (C) 1992. B and G adapted from Feng et al. 1996; reproduced, with permission, from The Rockefeller University Press (C) 1996. F adapted from Feng et al. 1999a; reproduced, with permission, from John Wiley and Sons (C) 1999.) 


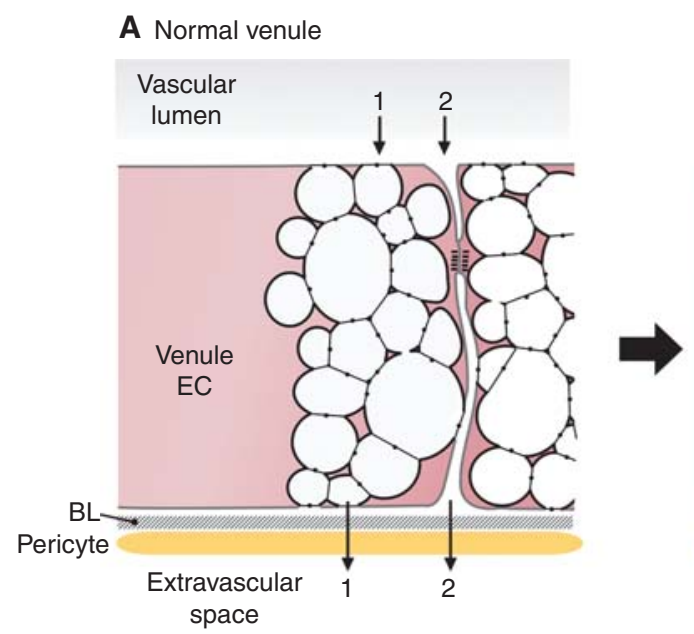

B AVH

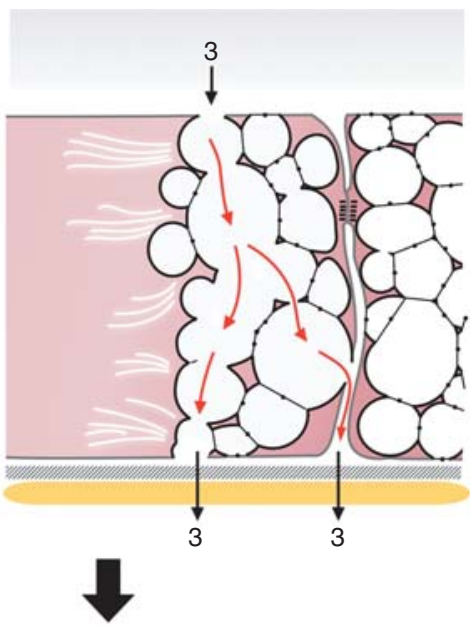

C $\mathrm{CVH}$

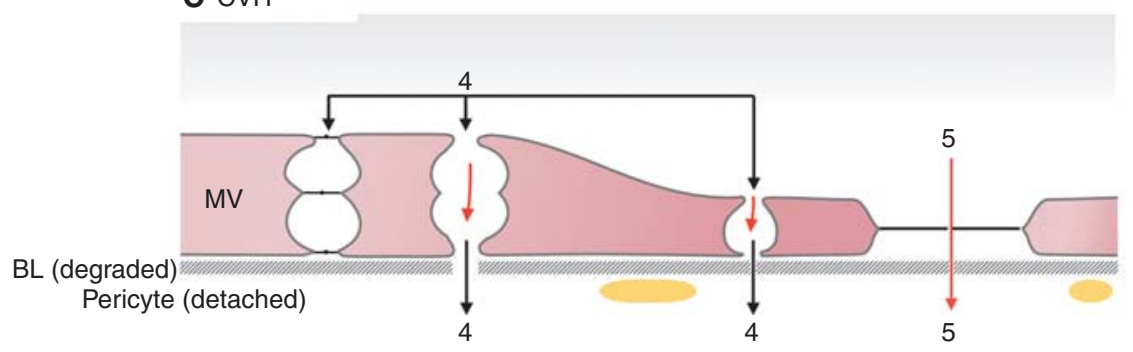

Figure 3. Pathways of acute and chronic vascular hyperpermeability. (A) Schematic diagram of a normal venule comprised of cuboidal endothelium with prominent VVOs and closed interendothelial cell junctions. Note that some VVO vesicles attach to the intercellular cleft below the tight and adherens junctions. 1 and 2 indicate potential pathways for transcellular (VVO) and intercellular ( paracellular) plasma extravasation, respectively. Basal lamina (BL) is intact and the endothelium is covered by pericytes. (B) AVH. Acute exposure to VEGF-A causes VVOs to open, allowing transcellular passage of plasma contents, possibly by mechanical pulling apart of stomatal diaphragms. Others have suggested that fluid extravasation takes place through an opening of intercellular junctions. (C) CVH. Prolonged VEGF-A stimulation causes venules to transform into MVs. Plasma may extravasate either through residual VVO vesicles (4) or through fenestrae (5). (Figure adapted from Nagy et al. 2008a; reproduced, with permission, from Springer (C) 2008.)

(Chang et al. 2009a). This raises the possibility that caveolin-1, although not necessary for VVO formation, is necessary for their proper function. Further evidence to this effect is that angiogenesis and $\mathrm{CVH}$ are also greatly reduced in caveolin-1 $1^{-/-}$mice (see below).

Although very little is known about the mechanisms of VVO function, it is clear that, with exposure to histamine, VPF/VEGF-A, etc., large macromolecular tracers such as ferritin pass through a sequence of interconnected VVO vesicles and vacuoles from the vascular lumen to the ablumen (Figs. 2D,E and 3)
(Feng et al. 1996, 1997). It seems that vascular permeability-inducing agents cause the diaphragms interconnecting vesicles and vacuoles to open, thereby providing a transcellular pathway for plasma and plasma protein extravasation. The underlying mechanism could be mechanical, as was Majno's endothelial cell contraction model (Majno et al. 1969). If so, endothelial cell-cell junctions would serve as intact "anchors" and the actin-myosin contractions induced by permeability factors would pull apart the diaphragms linking adjacent VVO vesicles and vacuoles, resulting in a transcellular 
J.A. Nagy et al.

rather than a paracellular route of plasma extravasation (Fig. 3B). Determining whether solutes cross venular endothelium by inter- or transcellular (by VVOs) pathways is difficult because of the tortuosity of the interendothelial cell interface and the proximity of VVOs to that interface (Fig. 3A,B). Electron microscopic three-dimensional reconstructions have demonstrated that many of the openings induced in venular endothelium by permeability factors are in fact transendothelial cell pores (Fig. 4) (Neal and Michel 1995; Feng et al. 1997, 1999a). To demonstrate for sure that a pore is paracellular it would be necessary to localize specialized junction proteins such as VE-cadherin in the plasma membrane bordering the pore (e.g., by electron microscopic immunocytochemistry), an enormously difficult feat.

\section{Chronic Vascular Hyperpermeability}

Whereas acute exposure to VEGF-A causes an immediate but self-limited hyperpermeability of normal venules, chronic exposure induces profound changes in venular structure and function. Together, these result in the chronic hyperpermeability of pathological angiogenesis as found in tumors (Fig. 5A-C), healing wounds, and chronic inflammatory diseases such as rheumatoid arthritis, psoriasis, cellular immunity, etc. (Nagy et al. 1995; Dvorak 2003, 2007b). As in AVH, the fluid that extravasates is an exudate whose protein content approaches that of plasma.

In contrast to the capillaries and venules involved in BVP and AVH, the blood vessels that leak in $\mathrm{CVH}$ do not correspond to any type of normal blood vessel. Instead, they consist

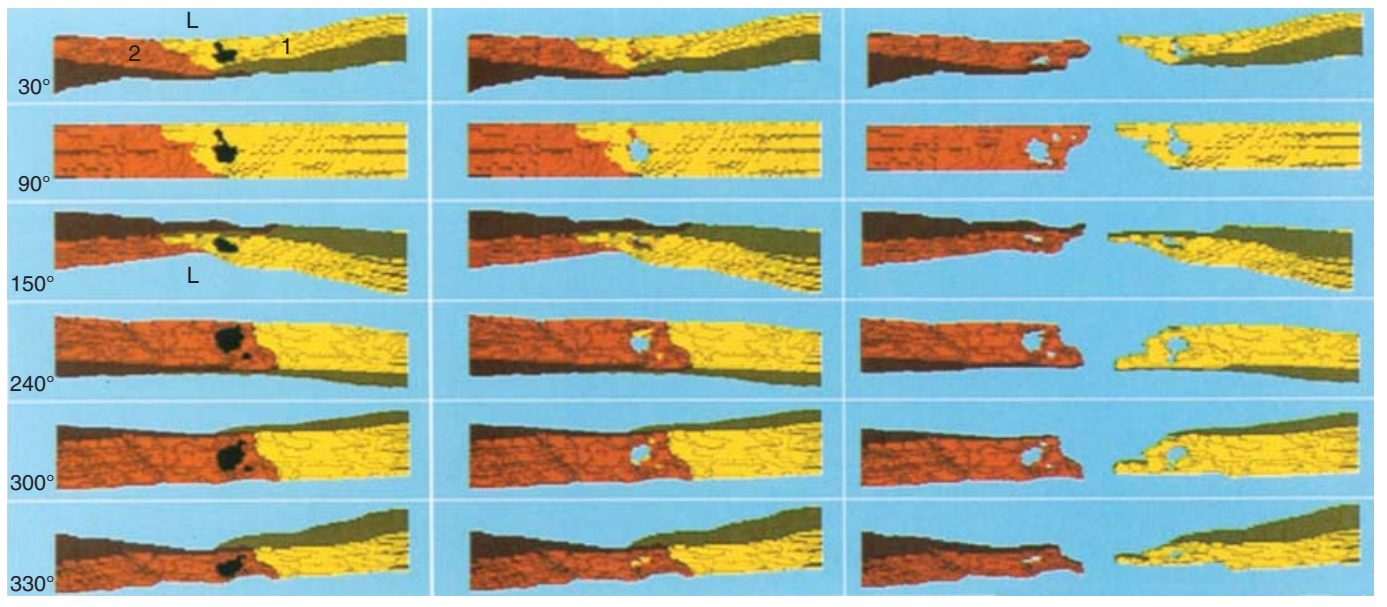

Figure 4. Computer-generated three-dimensional reconstruction of serial electron microscope sections of a colloidal carbon-filled pore induced in rat cremaster venule by VPF/VEGF-A. Panels represent successive rotations toward the viewer around a horizontal axis at the angles indicated. $0^{\circ}$ (not shown) corresponds to a vascular cross section taken at right angles to the direction of blood flow and $90^{\circ}$ corresponds to a view looking down on the luminal surface; views $\geq 240^{\circ}$ illustrate the abluminal surface. Endothelial cells are labeled 1 (yellow) and 2 (orange-brown). Tracer colloidal carbon (black) fills the pores in the left panels. In the middle panels, carbon was deleted from the reconstruction to facilitate visualization into the pore interior, which is seen to pass transcellularly through the cytoplasm of both endothelial cells, revealing the underlying turquoise background. A small portion of the large pore, which passes through cell 1 (yellow), does not traverse cell 2, as evidenced by the underlying orange-brown background (middle panel, $30^{\circ}$ and $90^{\circ}$ ). Also, a second smaller pore, as well as small portions of the larger pore, penetrate cell 2 without passing through cell 1 (recognized by yellow instead of turquoise background in panels $\geq 240^{\circ}$ ). Right panels depict endothelial cells 1 and 2 separately, again with carbon deleted. (L) Lumen. (Figure adapted from Feng et al. 1997; reproduced, with permission, from Wiley-Blackwell (C) 1997.) 

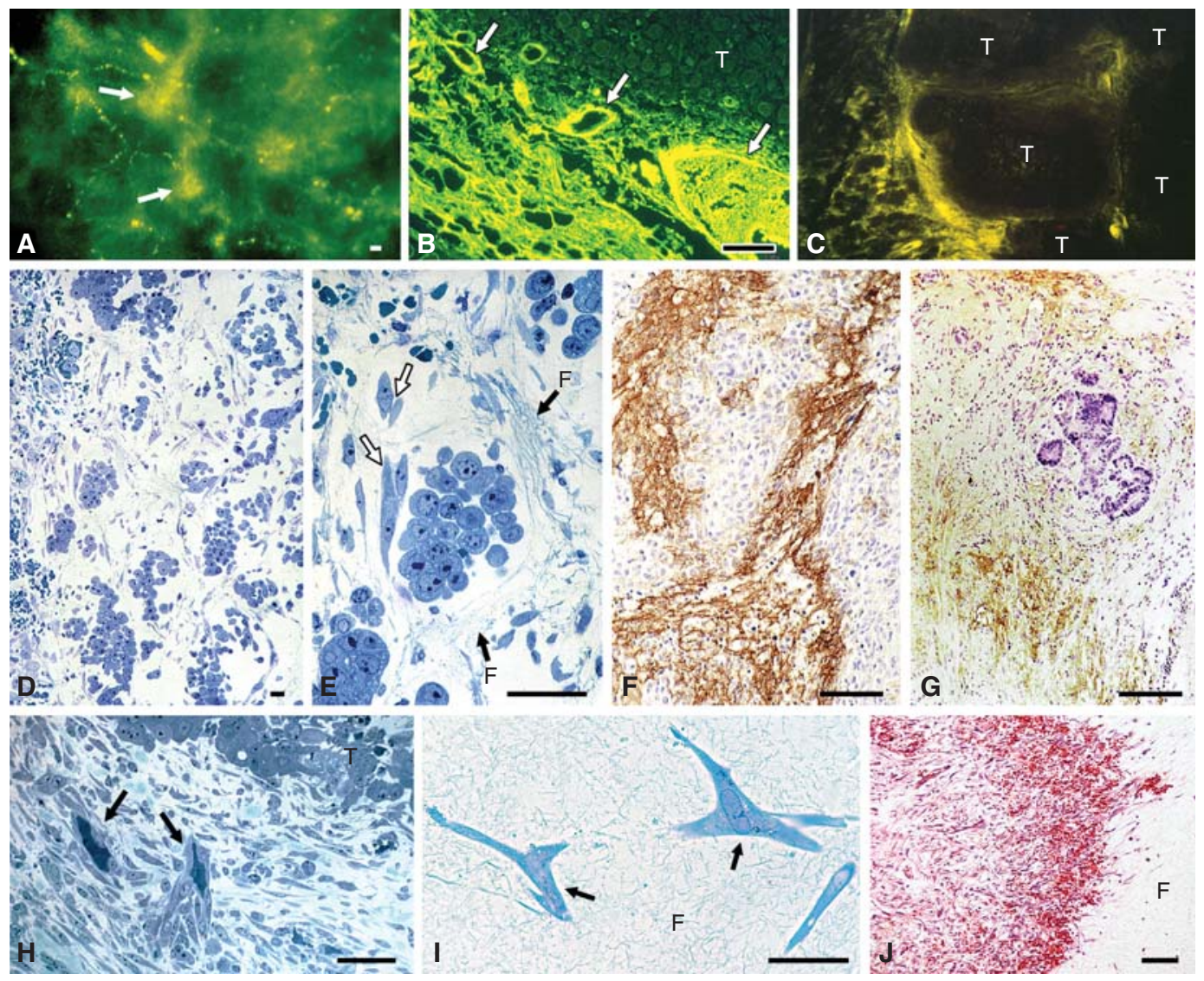

Figure 5. Chronic vascular hyperpermeability and tumor stroma generation. $(A-C)$ Blood vessels (arrows) supplying line 10 guinea pig tumors are hyperpermeable to circulating macromolecular fluoresceinated dextran, outlining tumor nodules. $(D, E)$ Line 10 tumor cells $48 \mathrm{~h}$ after transplant into the subcutaneous space of syngeneic strain 2 guinea pigs. Fibrin forms a water-trapping gel (F) that serves as a provisional stroma that separates tumor cells into discrete islands and that provides a favorable matrix for fibroblast (white arrows) and endothelial cell migration. ( $F, G)$ Immunohistochemical demonstration of fibrin (brown staining) in guinea pig line 1 and human colorectal adenocarcinoma, respectively. $(H)$ Fibroblasts and blood vessels (black arrows) invade line 1 tumor fibrin gel, replacing it with fibrous connective tissue. (I) Fibroblasts (arrows) migrate through fibrin gel (F) in culture. $(J)$ Implanted fibrin gel (F) in subcutaneous space is replaced by ingrowing fibroblasts and new blood vessels, creating granulation-like vascular connective tissue. Scale bars, $25 \mu \mathrm{m}(B, I), 50 \mu \mathrm{m}(A, C, D, H)$, and $100 \mu \mathrm{m}(E, F, J)$. (A-F and $H-J$ adapted from Dvorak 2003; reproduced, with permission, from the author. $G$ adapted from Dvorak et al. 1988; reproduced, with permission, from the American Journal of Pathology (C) 1988.)

largely of "mother" vessels (MVs), a welldefined subset of the several types of new and highly abnormal blood vessels that form in tumors and other examples of pathological angiogenesis (Dvorak 2003; Nagy et al. 2007, 2010). MVs begin to develop within hours after injection of tumor cells into mice, and similar MVs form in healing wounds and in nude mouse tissues injected with an adenovirus expressing VEGF-A ${ }^{164}$ (Ad-VEGF-A ${ }^{164}$ ).

MVs are greatly enlarged sinusoids that arise from preexisting normal venules by a process that initially involves vascular basement membrane (VBM) degradation, followed by pericyte detachment, extensive endothelial cell thinning, and a substantial increase in lumen 
J.A. Nagy et al.

size (Figs. 2C and 3C). VBMs are noncompliant (nonelastic) structures that limit microvessel expansion to $\sim 30 \%$ (Swayne et al. 1989). Therefore, to acquire a cross-sectional area that is four- to fivefold greater than that of the venules from which they arise, VBM must be degraded. Recent data have shown that two important VBM components, collagen IV and laminin $\beta 1$ chain, are degraded in developing MVs in both tumors and at Ad-VEGF-A ${ }^{164}$ injection sites (Chang et al. 2009b). Surprisingly, matrix metalloproteases did not seem to be involved. Instead, VBM degradation resulted from an altered balance between cathepsins $(\mathrm{B}>\mathrm{S}>\mathrm{L})$ and their endogenous, highaffinity competitive inhibitors, a family of small $(11-13 \mathrm{kDa})$ proteins called cysteine protease inhibitors (CPIs). Pericytes of venules that were evolving into MVs were identified as the source of increased cathepsin expression and activity (Chang et al. 2009b). In parallel, expression of several CPIs, including stefin A (cystatin A) and cystatins B and C, was strikingly reduced in developing MVs. Taken together, these data indicate that MV formation results from an upsetting of the normal cathepsin/CPI balance that regulates vascular size. Increased pericyte cathepsins, relieved of CPI inhibition, degrade VBM, causing pericytes to detach, resulting in MVs that are lined only by endothelial cells.

Vascular enlargement, the final step in MV formation, is likely driven by centripetal vascular pressure on endothelial cells that have lost the constraints normally imposed by VBM and pericytes. To accommodate this increase in luminal size, MV endothelial cells thin and expand to cover a greatly enlarged surface area, a process that requires substantial increases in plasma membrane. Although some membrane may derive from new synthesis, a significant amount comes from the transfer to the cell surface of membrane that is normally stored in the venular endothelial cell cytoplasm in the form of VVOs. Thus, in addition to providing a pathway for transcellular extravasation of plasma from normal venules in response to acute exposure to vascular permeabilizing factors (Dvorak et al. 1996; Feng et al. 1996, 1997, 2000), VVOs have a second function, that of contributing their membrane to the cell surface to provide the additional plasma membrane required to cover an enlarged surface area (Nagy et al. 2006, 2007). As noted above, CVH and MV formation are strikingly deficient in caveolin-1 ${ }^{-/-}$ mice (Chang et al. 2009a).

MVs are transient structures that do not persist long before evolving into several different types of "daughter" vessels. Only one of these, glomeruloid microvascular proliferations (GMPs), is hyperpermeable. GMPs are poorly organized vascular structures that are so named because of their macroscopic resemblance to renal glomeruli (Pettersson et al. 2000; Sundberg et al. 2001). They are present in a variety of human tumors, particularly those such as glioblastoma multiforme that make unusually large amounts of VPF/VEGF-A; however, they are also found in breast and other carcinomas where their presence has been associated with an unfavorable prognosis (Straume et al. 2002; Goffin et al. 2003). The mechanisms by which GMPs form from MVs have been described elsewhere (Sundberg et al. 2001).

\section{Pathways of Macromolecular Extravasation from MVs and GMPs}

There continues to be considerable debate as to the pathways by which macromolecules cross hyperpermeable tumor blood vessels (Roberts and Palade 1995; McDonald et al. 1999; Feng et al. 2000). Our data indicate that macromolecules such as ferritin or peroxidase extravasate from MVs and GMPs largely by a transcellular route (Figs. 2D and 3C) (Nagy et al. 2006, 2008a). MVs and GMPs contain many fewer and less complex VVOs than normal venular endothelium. However, the path length for molecular extravasation is also greatly shortened, such that tracers need to pass through only a few, often only one or two, vesicles or vacuoles to reach the ablumen. Macromolecules also extravasate through fenestrae that develop in both MVs and GMPs (Figs. 2F and $3 \mathrm{C}$ ). Pores of the type that have been described in AVH (Fig. 4) have also been found in the endothelial cells of blood vessels supplying tumors (Roberts and Palade 1995), and as in 
$\mathrm{AVH}$, there is debate as to whether these pores are trans- or paracellular.

\section{VASCULAR HYPERPERMEABILITY AND STROMA FORMATION}

Vascular hyperpermeability results not only in the leakage of albumin and immunoglobulins, but also of fibrinogen and other clotting proteins such as factors V, VII, X, XIII, and prothrombin. These interact with tissue factor, a protein that is expressed by many tumor and normal mesenchymal cells, to activate the clotting system with two major consequences: conversion of extravasated plasma to serum and extravascular deposition of fibrin (Dvorak et al. 1981; VanDeWater et al. 1985). Both of these events have important sequelae. Normally, interstitial cells are bathed in a plasma protein-poor filtrate. However, vascular hyperpermeability changes the composition of the interstitial fluid dramatically. Not only is the fluid enriched in proteins, but with clotting it has also changed from plasma to serum. Serum has been shown to cause dramatic changes in the gene expression patterns of cultured mesenchymal cells (Chang et al. 2004), and it is likely that similar changes occur in vivo, though experiments to test this possibility have not as yet been performed.

Insertion of fibrin into tissues also has important consequences. Fibrin takes the form of a gel that traps water and other solutes, thereby inhibiting their clearance by lymphatic vessels or capillaries and resulting in tissue edema (Fig. 5D,E). Fibrin also serves as a "provisional" stroma, providing a matrix that initially organizes tumors into parenchymal and stromal compartments, before being replaced by mature stroma (Fig. 5D-H) (Dvorak et al. 1979a). The amount of fibrin present at any one time represents a balance between fibrin deposition and degradation. Degradation is thought to result primarily from plasmin, the protease generated when another leaked plasma protein, plasminogen, is activated by tumorsecreted plasminogen activator.

With RGD and other sequences that are recognized by $\alpha v \beta 3$ and other integrins, fibrin provides a favorable matrix for the migration of tumor, mesenchymal, and inflammatory cells (Senger 1996; Hynes 2009). The capacity of fibrin to support cell migration can be readily demonstrated in vitro (Fig. 5I). When adherent fibroblasts are overlaid with appropriately constituted fibrin gels, they migrate upward into and through these gels even in the absence of chemotactic factors (Brown et al. 1993). Other plasma proteins that extravasate from leaky blood vessels include fibronectin, vitronectin, and osteopontin. These likely also contribute to cell migration by virtue of sequences that favor cell attachment and detachment (Joshi et al. 1993; Hauptmann et al. 1995; Senger 1996). Fibronectin may also be integrated into fibrin as the result of factor XIII-mediated crosslinking.

Fibrin has additional properties that contribute to angiogenesis and mature stroma formation. Some of these are clearly understood. For example, fibrin binds to and thereby sequesters growth factors, protecting them from degradation. It also induces the expression of proangiogenic molecules such as IL-8 and tissue factor. Fragment E, a fibrin breakdown product, is directly proangiogenic (Dvorak and Rickles 2006; Dvorak 2007b). Less clearly understood are other mechanisms by which fibrin provides an environment in which endothelial cells organize to form blood vessels and in which fibroblasts synthesize and secrete the matrix proteins and proteoglycans characteristic of mature stroma. Together with macrophages, fibroblasts degrade the provisional fibrin stroma and eventually replace it by synthesizing mature stromal proteins. The vessel-promoting properties of fibrin have been demonstrated in vitro. Endothelial cells cultured as a monolayer on fibrin gels rapidly organized into vascular structures when they were overlaid with a second layer of fibrin (Chalupowicz et al. 1995). The stroma-promoting properties of fibrin have also been demonstrated in vivo by experiments in which fibrin gels were planted into the subcutaneous space of guinea pigs (Dvorak et al. 1987). Fibroblasts and new blood vessels soon entered these gels and proceeded to synthesize collagen and replace fibrin with granulation 
J.A. Nagy et al.

tissue similar to that deposited in tumors and healing wounds (Fig. 5J). Some of the proteins that comprise granulation tissue, such as types I and III collagen, are also abundant in normal adult tissues. However, granulation tissue also includes tenascin, alternatively spliced forms of fibronectin, and proteoglycans that are not normally expressed in most normal adult tissues (Yeo et al. 1991; Hauptmann et al. 1995; Hashimoto-Uoshimka et al. 1997; Sage 1997).

\section{CONCLUDING REMARKS}

In summary, vascular permeability occurs in three contexts, that of the low-level basal permeability of normal tissues and the greatly increased permeability of acute and chronic pathologic states, which are often associated with acute release or chronic synthesis and release of VPF/VEGF-A. Different types of blood microvessels participate in each of the three contexts. Also, the composition of the extravasate differs: a low protein transudate in the case of BVP, and high plasma protein exudates in the case of $\mathrm{AVH}$ and $\mathrm{CVH}$. Although much remains to be learned, plasma and plasma proteins apparently traverse endothelial cells by both transcellular and paracellular pathways in all three contexts.

$\mathrm{CVH}$ and its consequences of fibrin deposition, angiogenesis, and stroma generation have long been known to be important features of healing wounds, whether in the form of cuts or bruises in skin or healing myocardial infarcts and strokes (Haddow 1974; Dvorak 1986, 2003). It is now clear that tumors have co-opted this response by secreting VPF/VEGF in amounts similar to those found in healing wounds. Whether in wounds or tumors, secretion of VPF/VEGF leads to deposition of a fibrin gel provisional stroma that changes the extracellular matrix of normal tissues from anti- to pro- angiogenic and stromagenic. This new matrix favors and supports inward migration of mesenchymal and inflammatory cells, new blood vessel formation, and the laying down of granulation tissue and subsequent mature matrix that resembles but is nonetheless distinct from the connective tissue found in normal adults. The amount of mature stroma that results depends on many factors, such as the extent of leakage, activation of clotting and fibrinolysis, etc. The end result is scar formation in the case of healed wounds and desmoplasia in the case of tumors. The process of tumor angiogenesis thus differs strikingly from that of the physiological angiogenesis of development in which newly forming vessels are structurally normal and not hyperpermeable.

\section{ACKNOWLEDGMENTS}

This work was supported by National Institutes of Health grants P01 CA92644 and R01CA142262 and by a contract from the National Foundation for Cancer Research.

\section{REFERENCES}

Bates DO, Harper SJ. 2003. Regulation of vascular permeability by vascular endothelial growth factors. Vascul Pharmacol 39: 225-237.

Boesiger J, Tsai M, Maurer M, Yamaguchi M, Brown LF, Claffey KP, Dvorak HF, Galli SJ. 1998. Mast cells can secrete vascular permeability factor/vascular endothelial cell growth factor and exhibit enhanced release after immunoglobulin E-dependent upregulation of Fce receptor I expression. J Exp Med 188: 1135-1145.

Brown LF, Lanir N, McDonagh J, Czarnecki K, Estrella P, Dvorak AM, Dvorak HF. 1993. Fibroblast migration in fibrin gel matrices. Am J Pathol 142: 273-283.

Chalupowicz DG, Chowdhury ZA, Bach TL, Barsigian C, Martinez J. 1995. Fibrin II induces endothelial cell capillary tube formation. J Cell Biol 130: 207-215.

Chang HY, Sneddon JB, Alizadeh AA, Sood R, West RB, Montgomery K, Chi JT, van de Rijn M, Botstein D, Brown PO. 2004. Gene expression signature of fibroblast serum response predicts human cancer progression: Similarities between tumors and wounds. PLoS Biol 2: E7. doi: 10.1371/journal.pbio.0020007.

Chang SH, Feng D, Nagy JA, Sciuto TE, Dvorak AM, Dvorak HF. 2009a. Vascular permeability and pathological angiogenesis in caveolin-1-null mice. Am J Pathol 175: $1768-1776$.

Chang SH, Kanasaki K, Gocheva V, Blum G, Harper J, Moses MA, Shih SC, Nagy JA, Joyce J, Bogyo M, et al. 2009b. VEGF-A induces angiogenesis by perturbing the cathepsin-cysteine protease inhibitor balance in venules, causing basement membrane degradation and mother vessel formation. Cancer Res 69: 4537-4544.

Curry FR. 2005. Microvascular solute and water transport. Microcirculation 12: 17-31.

Dvorak HF. 1986. Tumors: Wounds that do not heal. Similarities between tumor stroma generation and wound healing. N Engl J Med 315: 1650-1659. 
Dvorak HF. 2003. Rous-Whipple Award Lecture. How tumors make bad blood vessels and stroma. Am J Pathol 162: $1747-1757$.

Dvorak A. 2007a. Electron microscopic-facilitated understanding of endothelial cell biology: Contributions established during the 1950s and 1960s. In Endothelial biomedicine (ed. Aird W), pp. 643-656. Cambridge University Press, New York.

Dvorak H. 2007b. Tumor blood vessels. In Endothelial biomedicine (ed. Aird W), pp. 1457-1470. Cambridge University Press, New York.

Dvorak HF, Rickles FR. 2006. Hemostasis and thrombosis in cancer. In Hemostasis and thrombosis: Basic principles and clinical practice (ed. Colman RW, Marder VJ, Clowes AW, et al.), pp. 851-873. Lippincott Williams \& Wilkins, Philadelphia.

Dvorak HF, Dvorak AM, Manseau EJ, Wiberg L, Churchill WH. 1979a. Fibrin gel investment associated with line 1 and line 10 solid tumor growth, angiogenesis, and fibroplasia in guinea pigs. Role of cellular immunity, myofibroblasts, microvascular damage, and infarction in line 1 tumor regression. J Natl Cancer Inst 62: 1459-1472.

Dvorak HF, Orenstein NS, Carvalho AC, Churchill WH, Dvorak AM, Galli SJ, Feder J, Bitzer AM, Rypysc J, Giovinco P. 1979b. Induction of a fibrin-gel investment: An early event in line 10 hepatocarcinoma growth mediated by tumor-secreted products. J Immunol 122: 166-174.

Dvorak HF, Quay SC, Orenstein NS, Dvorak AM, Hahn P, Bitzer AM, Carvalho AC. 1981. Tumor shedding and coagulation. Science 212: 923-924.

Dvorak HF, Harvey VS, Estrella P, Brown LF, McDonagh J, Dvorak AM. 1987. Fibrin containing gels induce angiogenesis. Implications for tumor stroma generation and wound healing. Lab Invest 57: 673-686.

Dvorak HF, Nagy JA, Dvorak JT, Dvorak AM. 1988. Identification and characterization of the blood vessels of solid tumors that are leaky to circulating macromolecules. Am J Pathol 133: 95-109.

Dvorak AM, Kohn S, Morgan ES, Fox P, Nagy JA, Dvorak HF. 1996. The vesiculo-vacuolar organelle (VVO): A distinct endothelial cell structure that provides a transcellular pathway for macromolecular extravasation. J Leukoc Biol 59: $100-115$.

Feng D, Nagy JA, Hipp J, Dvorak HF, Dvorak AM. 1996. Vesiculo-vacuolar organelles and the regulation of venule permeability to macromolecules by vascular permeability factor, histamine, and serotonin. J Exp Med 183: 1981-1986.

Feng D, Nagy JA, Hipp J, Pyne K, Dvorak HF, Dvorak AM. 1997. Reinterpretation of endothelial cell gaps induced by vasoactive mediators in guinea-pig, mouse, and rat: Many are transcellular pores. J Physiol 504: 747-761.

Feng D, Nagy JA, Pyne K, Dvorak HF, Dvorak AM. 1998. Neutrophils emigrate from venules by a transendothelial cell pathway in response to FMLP. J Exp Med 187: 903-915.

Feng D, Nagy JA, Pyne K, Hammel I, Dvorak HF, Dvorak AM. 1999a. Pathways of macromolecular extravasation across microvascular endothelium in response to VPF/ VEGF and other vasoactive mediators. Microcirculation 6: $23-44$.
Feng Y, Venema VJ, Venema RC, Tsai N, Behzadian MA, Caldwell RB. 1999b. VEGF-induced permeability increase is mediated by caveolae. Invest Ophthalmol Vis Sci 40: $157-167$.

Feng D, Nagy J, Dvorak A, Dvorak H. 2000. Different pathways of macromolecule extravasation from hyperpermeable tumor vessels. Microvasc Res 59: 24-37.

Galli SJ. 2000. Mast cells and basophils. Curr Opin Hematol 7: $32-39$.

Goffin JR, Straume O, Chappuis PO, Brunet JS, Begin LR, Hamel N, Wong N, Akslen LA, Foulkes WD. 2003. Glomeruloid microvascular proliferation is associated with p53 expression, germline BRCA1 mutations and an adverse outcome following breast cancer. $\mathrm{Br} \mathrm{J}$ Cancer 89: $1031-1034$.

Guyton A, Hall J. 2000. Textbook of medical physiology. Saunders, Philadelphia.

Haddow A. 1974. Addendum to "Molecular repair, wound healing, and carcinogenesis: Tumor production a possible overhealing?" Adv Cancer Res 20: 343-366.

Hashimoto-Uoshimka M, Zhuo Yan Y, Schneider G, Aukhil I. 1997. The alternatively spliced domains EIIIB and EIIIA of human fibronectin affect cell adhesion and spreading. J Cell Sci 110: 2271-2280.

Hauptmann S, Zardi L, Siri A, Carnemolla B, Borsi L, Castellucci M, Klosterhalfen B, Hartung P, Weis J, Stocker G, et al. 1995. Extracellular matrix proteins in colorectal carcinomas. Expression of tenascin and fibronectin isoforms. Lab Invest 73: 172-182.

Hynes RO. 2009. The extracellular matrix: Not just pretty fibrils. Science 326: 1216-1219.

Joshi P, Chung CY, Aukhil I, Erickson HP. 1993. Endothelial cells adhere to the RGD domain and the fibrinogen-like terminal knob of tenascin. J Cell Sci 106: 389-400.

Kamei M, Carman CV. 2010. New observations on the trafficking and diapedesis of monocytes. Curr Opin Hematol 17: 43-52.

Karnovsky MJ. 1967. The ultrastructural basis of capillary permeability studied with peroxidase as a tracer. J Cell Biol 35: 213-236.

Kohn S, Nagy JA, Dvorak HF, Dvorak AM. 1992. Pathways of macromolecular tracer transport across venules and small veins. Structural basis for the hyperpermeability of tumor blood vessels. Lab Invest 67: 596-607.

Majno G, Palade GE, Schoefl GI. 1961. Studies on inflammation. II. The site of action of histamine and serotonin along the vascular tree: A topographic study. J Biophys Biochem Cytol 11: 607-626.

Majno G, Shea SM, Leventhal M. 1969. Endothelial contraction induced by histamine-type mediators: An electron microscopic study. J Cell Biol 42: 647-672.

McDonald DM, Thurston G, Baluk P. 1999. Endothelial gaps as sites for plasma leakage in inflammation. Microcirculation 6: 7-22.

Michel CC, Curry FE. 1999. Microvascular permeability. Physiol Rev 79: 703-761.

Miles AA, Miles EM. 1952. Vascular reactions to histamine, histamine-liberator and leukotaxine in the skin of guinea-pigs. J Physiol 118: 228-257.

Nagy JA, Masse EM, Herzberg KT, Meyers MS, Yeo KT, Yeo TK, Sioussat TM, Dvorak HF. 1995. Pathogenesis of 
J.A. Nagy et al.

ascites tumor growth: Vascular permeability factor, vascular hyperpermeability, and ascites fluid accumulation. Cancer Res 55: 360-368.

Nagy JA, Feng D, Vasile E, Wong WH, Shih SC, Dvorak AM, Dvorak HF. 2006. Permeability properties of tumor surrogate blood vessels induced by VEGF-A. Lab Invest 86: 767-780.

Nagy JA, Dvorak AM, Dvorak HF. 2007. VEGF-A and the induction of pathological angiogenesis. Annu Rev Pathol 2: $251-275$.

Nagy JA, Benjamin L, Zeng H, Dvorak AM, Dvorak HF. 2008a. Vascular permeability, vascular hyperpermeability and angiogenesis. Angiogenesis 11: 109-119.

Nagy JA, Shih SC, Wong WH, Dvorak AM, Dvorak HF 2008b. The adenoviral vector angiogenesis/lymphangiogenesis assay. Methods Enzymol 444: 43-64.

Nagy JA, Chang SH, Shih SC, Dvorak AM, Dvorak HF. 2010 Heterogeneity of the tumor vasculature. Semin Thromb Hemost 36: 321-331.

Neal CR, Michel CC. 1995. Transcellular gaps in microvascular walls of frog and rat when permeability is increased by perfusion with the ionophore A23187. J Physiol 488: 427-437.

Palade G. 1988. The microvascular endothelium revisited. In Endothelial cell biology in health and disease (ed. Simionescu N, Simionescu M), pp. 3-22. Plenum Press, New York.

Pappenheimer JR. 1953. Passage of molecules through capillary walls. Physiol Rev 33: 387-423.

Pettersson A, Nagy JA, Brown LF, Sundberg C, Morgan E, Jungles S, Carter R, Krieger JE, Manseau EJ, Harvey VS, et al. 2000. Heterogeneity of the angiogenic response induced in different normal adult tissues by vascular permeability factor/vascular endothelial growth factor. $L a b$ Invest 80: 99-115.

Rippe B, Haraldsson B. 1994. Transport of macromolecules across microvascular walls: The two-pore theory. Physiol Rev 74: 163-219.

Roberts WG, Palade GE. 1995. Increased microvascular permeability and endothelial fenestration induced by vascular endothelial growth factor. J Cell Sci 108: 2369-2379.
Rosengren BI, Rippe A, Rippe C, Venturoli D, Sward K, Rippe B. 2006. Transvascular protein transport in mice lacking endothelial caveolae. Am J Physiol Heart Circ Physiol 291: H1371-H1377.

Sage EH. 1997. Terms of attachment: SPARC and tumorigenesis. Nat Med 3: 144-146.

Schubert W, Frank PG, Woodman SE, Hyogo H, Cohen DE, Chow CW, Lisanti MP. 2002. Microvascular hyperpermeability in caveolin- $1^{-/-}$knock-out mice. Treatment with a specific nitric-oxide synthase inhibitor, L-NAME, restores normal microvascular permeability in Cav-1 null mice. J Biol Chem 277: 40091-40098.

Senger DR. 1996. Molecular framework for angiogenesis: A complex web of interactions between extravasated plasma proteins and endothelial cell proteins induced by angiogenic cytokines. Am J Pathol 149: 1-7.

Senger DR, Galli SJ, Dvorak AM, Perruzzi CA, Harvey VS, Dvorak HF. 1983. Tumor cells secrete a vascular permeability factor that promotes accumulation of ascites fluid. Science 219: 983-985.

Stan RV. 2007. Endothelial stomatal and fenestral diaphragms in normal vessels and angiogenesis. J Cell Mol Med 11: 621-643.

Straume O, Chappuis PO, Salvesen HB, Halvorsen OJ, Haukaas SA, Goffin JR, Begin LR, Foulkes WD, Akslen LA 2002. Prognostic importance of glomeruloid microvascular proliferation indicates an aggressive angiogenic phenotype in human cancers. Cancer Res 62: 6808-6811.

Sundberg C, Nagy JA, Brown LF, Feng D, Eckelhoefer IA, Manseau EJ, Dvorak AM, Dvorak HF. 2001. Glomeruloid microvascular proliferation follows adenoviral vascular permeability factor/vascular endothelial growth factor164 gene delivery. Am J Pathol 158: 1145-1160.

Swayne GT, Smaje LH, Bergel DH. 1989. Distensibility of single capillaries and venules in the rat and frog mesentery. Int J Microcirc Clin Exp 8: 25-42.

VanDeWater L, Tracy PB, Aronson D, Mann KG, Dvorak HF 1985. Tumor cell generation of thrombin via functional prothrombinase assembly. Cancer Res 45: 5521-5525.

Yeo TK, Brown L, Dvorak HF. 1991. Alterations in proteoglycan synthesis common to healing wounds and tumors. Am J Pathol 138: 1437-1450. 


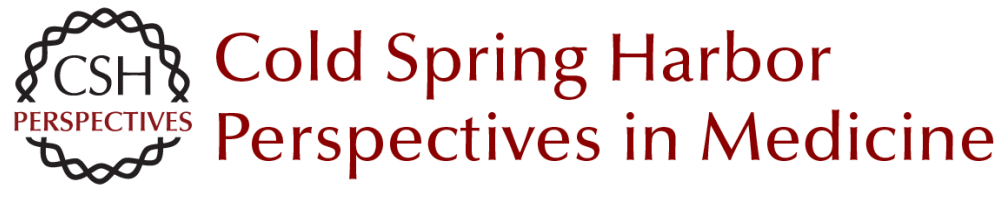

\section{Vascular Hyperpermeability, Angiogenesis, and Stroma Generation}

Janice A. Nagy, Ann M. Dvorak and Harold F. Dvorak

Cold Spring Harb Perspect Med 2012; doi: 10.1101/cshperspect.a006544 originally published online October 12, 2011

\section{Subject Collection Angiogenesis}

Extracellular Matrix Regulation of Vascular Morphogenesis, Maturation, and Stabilization George E. Davis and Scott S. Kemp

Endothelial Cell-Pericyte Interactions in the Pathogenesis of Cerebral Cavernous Malformations (CCMs) Wang Min and Jenny Huanjiao Zhou

Lymphatic Clearance and Pump Function Jerome W. Breslin

Platelets and (Lymph)angiogenesis Harvey G. Roweth and Elisabeth M. Battinelli

Modeling Brain Vasculature Immune Interactions In Vitro Ruth Lyck, Hideaki Nishihara, Sidar Aydin, et al.

Human Endothelial Colony-Forming Cells Juan M. Melero-Martin

\section{The Beauty and Complexity of Blood Vessel} Patterning

Victoria L. Bautch and Yoh-suke Mukouyama

Endothelialitis, Microischemia, and

Intussusceptive Angiogenesis in COVID-19 Steven J. Mentzer, Maximilian Ackermann and Danny Jonigk
Regulation of the Blood-Brain Barrier in Health and Disease

Cara C. Rada, Kanako Yuki, Jie Ding, et al.

Targeting Angiogenesis via Resolution of Inflammation

Abigail G. Kelly and Dipak Panigrahy

Notch Signaling in the Vasculature: Angiogenesis and Angiocrine Functions

Sana S. Hasan and Andreas Fischer

Signal Transduction and Gene Regulation in the Endothelium

Michel V. Levesque and Timothy Hla

Buttons and Zippers: Endothelial Junctions in

Lymphatic Vessels

Peter Baluk and Donald M. McDonald

Endothelial Cell Fate Determination: A Top Notch Job in Vascular Decision-Making

L.A. Naiche, Stephanie R. Villa and Jan K. Kitajewski

Leukocyte Trafficking in Lymphatic Vessels Aline Bauer, Hazal Tatliadim and Cornelia Halin

Lymphatic Tissue and Organ Engineering for In Vitro Modeling and In Vivo Regeneration Anna M. Kolarzyk, Gigi Wong and Esak Lee

For additional articles in this collection, see http://perspectivesinmedicine.cshlp.org/cgi/collection/ 